\title{
Peruna- ja juureskuorimoiden jätevedet ja niiden käsittely
}

\author{
Marja Lehto ja Ilkka Sipilä \\ MTT Kotieläintuotannon tutkimus, Vakolantie 55, 03400 Vihti, marja.lehto@mtt.fi, ilkka.sipila@mtt.fi
}

\section{Tiivistelmä}

Esikäsitellyn perunan ja juuresten kysyntä on jatkuvassa kasvussa. Pienimuotoista kuorimotoimintaa harjoitetaan tiloilla, jotka viljelevät itse kuorittavat perunat ja juurekset. Monet kuorimot ovat kuitenkin laajentuneet yrityksiksi, jotka ostavat muualta osan tai kaiken kuorittavan raaka-aineen. Raaka-aineen määrä tilakuorimoilla vaihtelee sadasta tonnista tuhansiin tonneihin vuodessa. Perunanja juuresten kuorinta on ympäristöluvanvaraista toimintaa ja uusissa luvissa edellytetään mm. tehokasta orgaanisen aineen sekä ravinteiden poistoa jätevesistä.

Pesu- ja kuorintaprosesseissa syntyy erilaisia jätevesiä, joiden laatu ja määrä vaihtelevat suuresti kuorintamenetelmästä riippuen. Perunoiden ja juuresten pesusta tulee multavettä ja multalietettä, kuorinnasta taas solunestettä ja kasviainesta sisältäviä vesiä sekä juuresten huuhteluvesiä. Tilojen ja laitteiden puhtaanapidosta muodostuu erilaisia pesuvesiä. Jätevesimäärät tilakuorimoilla vaihtelevat toiminnan koosta ja kuorintamenetelmistä riippuen yleensä 5 - $50 \mathrm{~m}^{3}$ päivässä. Keskikokoisen perunatai juureskuorimon jätevesikuormitus vastaa jopa tuhannen asukkaan taajaman puhdistamattomien jätevesien kuormitusta.

Kuorimotoiminnan jätevedet sisältävät paljon orgaanista ainetta, mikä on pääosin liukoisessa muodossa. Biologinen hapenkulutus on yleensä välillä $2000-10000 \mathrm{mg} / \mathrm{l}$. Jätevedet ovat myös happamia, pH 4 - 5, ja sisältävät runsaasti ravinteita, kuten fosforia ja typpeä.

Kuorimojätevedet on käsiteltävä tehokkaasti ennen niiden pääsyä ympäristöön. Jätevesien käsittelystä aiheutuu yritykselle huomattavia kustannuksia. Yrittäjän kannalta helppo ja kokonaiskustannuksiltaan edullinen ratkaisu olisi jäteveden johtaminen kunnalliseen tai paikalliseen jätevedenkäsittelylaitokseen. Haja-asutusalueilla viemäriverkkoon liittyminen on kuitenkin harvoin mahdollista.

Hankkeessa oli mukana kahdeksan kuorimoa, joiden jätevedenkäsittelyä seurattiin. Yhdessä yrityksessä oli panospuhdistamo ja toiseen sellainen rakennettiin hankkeen aikana, yhdessä oli biosuodin, kahdessa kohteessa kemiallinen jätevedenkäsittely ja laskeutusallas, yhdessä kohteessa laskeutusallas+imeytyskenttä+lammikko -käsittely. Yhdessä kohteessa selvitettiin mahdollisuutta liittyä kunnallisen jätevedenkäsittelyn piiriin.

Tutkituista jätevedenkäsittelymenetelmistä vain panospuhdistamolla päästiin tavoiteltuihin puhdistustuloksiin, typpi saatiin poistettua jopa yli odotusten

\section{Asiasanat}

jätevesien käsittely, vihannes, peruna, kuorimo 


\section{Johdanto}

Peruna- ja juureskuorimoissa muodostuvien jätevesien määrä ja laatu vaihtelee suuresti riippuen kuorittavasta lähtöaineesta, kuorintamenetelmästä, kuorintamäärästä ja veden käytöstä. Kuivakuorinnassa jätevesiä syntyy juuresten esikäsittelystä (mullanerotus, pesu), juuresten huuhtelusta sekä tuotantotilojen ja koneiden pesusta. Märkäkuorinnassa myös kuorintavaiheessa muodostuu jätevesiä. Muodostuvien jätevesien määrä vaihtelee kuorintamenetelmistä ja -määristä riippuen 5 - 50 $\mathrm{m}^{3}$ :iin päivässä. Kuvassa 1 . on esitetty kaaviokuva kuorintaprosessista sekä muodostuvista jäte- ja jätevesijakeista.

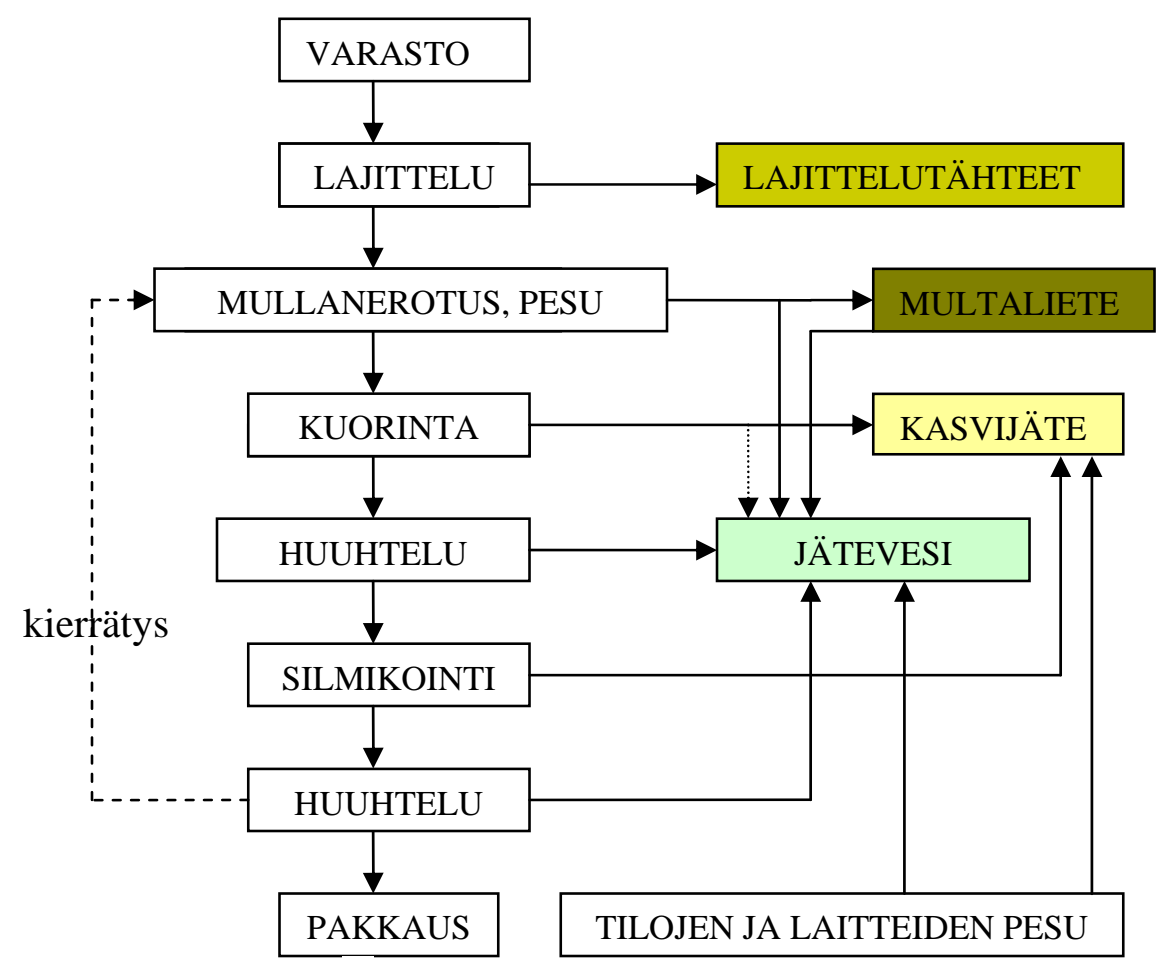

Kuva 1. Perunan ja juuresten kuorintaprosessi ja muodostuvat jakeet.

Biologinen hapenkulutus BOD ja kemiallinen hapenkulutus COD ovat yleisimmin käytettyjä jäteveden orgaanisen aineen kuvaajia. Yleensä COD > BOD ja monissa jätevesissä COD/BOD on vakio. Helcom (1996) on antanut elintarviketeollisuutta koskevan suosituksen 17/10 toiminnalle, josta tulee jätevesiä enemmän kuin $25 \mathrm{~m}^{3}$ vuorokaudessa. Suosituksessa on annettu pitoisuudet käsitellylle jätevedelle, päästöraja orgaaniselle aineelle on $0,75 \mathrm{~kg} / \mathrm{d}$, taulukko 1 .

Taulukko 1. Helcomin suositukset elintarviketeollisuuden jätevesille.

\begin{tabular}{ll}
\hline Suure & Käsitellyn jäteveden suurin pitoisuus \\
\hline $\mathrm{COD}$ & $250 \mathrm{mg} / \mathrm{l}$ \\
$\mathrm{BOD}_{7}$ & $30 \mathrm{mg} / \mathrm{l}$ \\
kok-P & $2 \mathrm{mg} / \mathrm{l}^{*}$ \\
$\mathrm{NH}_{4}-\mathrm{N}$ & $10 \mathrm{mg} / \mathrm{l}^{* *}$ \\
\hline
\end{tabular}

* puhdistamoille, joiden jätevesimäärä $>500 \mathrm{~m}^{3} / \mathrm{d}$, ** puhdistamon $\mathrm{T}>12{ }^{\circ} \mathrm{C}$. 
Peruna- ja juureskuorimotoiminnasta tuleville jätevesille on tyypillistä korkea orgaanisen aineen määrä eli jätevesissä on korkeat $\mathrm{BOD}_{7}$ sekä COD -pitoisuudet. Huomattava osa (75 \%) orgaanisesta aineesta on liukoisessa muodossa (Loehr 1974). Kuorittaessa juureksen pinta rikkoutuu ja veden joukkoon vapautuu solunestettä. Perunan solunesteen BOD $_{7}$-arvo on yleensä 10000 - $25000 \mathrm{mg} / \mathrm{l}$ (Lammentausta \& Oksjoki 2004). Perunan kuivakuorinnasta aiheutuva jätevesikuorma on $3-6 \mathrm{~kg}$ $\mathrm{BOD}_{7} /$ raaka-ainetonni ja perunan sekä porkkanan märkäkuorinnasta 5 - $15 \mathrm{~kg} \mathrm{BOD} /$ raaka-ainetonni (Henze et al. 1997). Kuorimolta tulevan jäteveden happamuus on tyypillisesti alhainen, pH on yleensä välillä $4-5$ ja jätevedet sisältävät myös runsaasti ravinteita.

Peruna- ja juureskuorimoiden ympäristöluvissa on käsittelyvaatimukset sekä orgaaniselle aineelle että fosforille, jolloin kyseeseen tulevat biologis-kemialliset jätevedenkäsittelymenetelmät. Jätevesien biologisessa käsittelyssä mikro-organismit, pääasiassa bakteerit, käyttävät jäteveden orgaanista ainetta ja epäorgaanisia suoloja kasvuunsa ja uuden solumateriaalin tuottamiseen. Osan orgaanisesta aineesta mikrobit käyttävät energiantarpeensa tyydyttämiseen (Kettunen ym. 2006). Käsittelyn tarkoituksena ei yleensä ole orgaanisen aineksen täydellinen hajottaminen, vaan tavoitteena on muuttaa jäteveteen liuenneet ja hienojakoiset aineet sellaiseen muotoon, että ne voidaan esimerkiksi laskeuttamalla erottaa vedestä (Karttunen 2004). Kuorimojätevesien orgaanisen aineksen, typen ja fosforin suhteet ovat usein sekä jätevesien biologiselle käsittelylle että ravinteiden biologiselle poistolle sopivia, optimi BOD 7 :N:P -suhde on 100:5:1 (Lammentausta \& Oksjoki 2004).

\section{Aineisto ja menetelmät}

Hankkeessa oli mukana kahdeksan kuorimoyritystä. Hankkeen yrityksistä yhdessä oli panospuhdistamo ja toiseen sellaista oltiin rakentamassa, yhdessä oli biosuodin, kahdessa kohteessa oli kemiallinen jäteveden käsittely ja laskeutusallas, yhdessä kohteessa jätevedet kerättiin lietealtaaseen ja levitettiin keväällä pellolle sekä yhdessä kohteessa oli laskeutusallas+imeytyskenttä+lammikko -käsittely. Yhdessä kohteessa selvitettiin mahdollisuutta liittyä kunnalliseen jätevedenkäsittelylaitokseen. Hankkeen aikana rakennettiin yksi uusi panospuhdistamo ja toisessa kohteessa tehtiin panospuhdistamon laajennus.

Hankkeessa mukana olleiden kuorimoiden jätevesien laatua ja määrää seurattiin vuosina 2004 2006. Jätevesinäytteistä tehtiin pikamäärityksinä ravinne- ja $\mathrm{COD}_{\mathrm{Cr}}$-analyyseja Langen kyvettitesteillä sekä virallisia analyysejä (BOD 7 , COD, typpi-, fosfori- ja kiintoainepitoisuudet) akkreditoidussa laboratoriossa. Kuorimoilta tulevan jäteveden näytteenotossa käytettiin automaattista ISCO 6700 näytteenotinta, jonka avulla kerättiin viikon kokoomanäytteet.

Puhdistamon päästöjä tarkastellessa pitäisi tarkastella kokonaiskuormituksia eli kuinka monta kg vuorokaudessa $(\mathrm{kg} / \mathrm{d})$ orgaanista ainetta tai ravinteita pääsee ympäristöön. Kuorimoissa järkevä seurantajakso jäteveden muodostumiselle on vähintään viikko, sillä toiminta ja jätevesien muodostuminen vaihtelee yleensä viikon sisällä päivittäin.

\section{Tulokset ja tulosten tarkastelu}

Hankkeenssa mukana olleista jäteveden käsittelymenetelmistä vain panospuhdistamolla päästiin tavoiteltuihin puhdistustuloksiin, typpi saatiin poistettua jopa yli odotusten, taulukko 2

Taulukko 2. Porkkanankuorimojätevesien käsittelyn tuloksia. Käsittely: biologis-kemiallinen panospuhdistamo, fosforin saostus rautasulfaatilla.

\begin{tabular}{|c|c|c|c|c|c|}
\hline \multicolumn{2}{|c|}{ Mitattu suure } & $\begin{array}{l}\text { Tuleva } \\
\text { jätevesi }\end{array}$ & $\begin{array}{l}\text { Lähtevä } \\
\text { jätevesi }\end{array}$ & Reduktio & $\begin{array}{l}\text { Kuormitus } \\
\mathrm{kg} / \mathrm{d}\end{array}$ \\
\hline $\mathrm{BOD}_{7}$ & $\mathrm{mg} / \mathrm{l}$ & 3300 & 10 & 99,7 & 0,2 \\
\hline COD & $\mathrm{mg} / \mathrm{l}$ & 4800 & 104 & 97,8 & 2,1 \\
\hline kok-P & $\mathrm{mg} / \mathrm{l}$ & 17,5 & 0,8 & 96,7 & 0,02 \\
\hline kok-N & $\mathrm{mg} / \mathrm{l}$ & 63,5 & 4,0 & 93,7 & 0,08 \\
\hline $\mathrm{pH}$ & & 5,2 & 7,8 & - & - \\
\hline kiintoaine & $\mathrm{mg} / \mathrm{l}$ & 955 & 35 & 96,3 & 0,7 \\
\hline $\mathrm{NH}_{4}^{+}$ & $\mathrm{mg} / \mathrm{l}$ & 2,5 & 0,04 & 94,4 & 0,0008 \\
\hline jätevesimä & rä m³/viikko & 100 & 100 & - & - \\
\hline
\end{tabular}


Kemiallisella saostuksella ja laskeutuksella voidaan jätevedessä olevia ainepitoisuuksia pienentää merkittävästi, mutta kuorimojätevesien käsittelymenetelmänä tämä ei ole sellaisenaan riittävä, taulukko 3. Hankkeessa mukana ollutta biosuodinta käytettiin laitevalmistajan ohjeiden mukaan. Suodin tukkeutui, koska pH oli biologiselle toiminnalle liian alhainen ja tärkkelys saostui biosuotimeen.

Taulukko 3. Perunankuorimojäteveden käsittelyn tuloksia. Käsittely: kemiallinen saostus alumiinisulfaatilla ja laskeutus, laskeutusaltaan koko $60 \mathrm{~m}^{3}$.

\begin{tabular}{llllll}
\hline \multicolumn{2}{l}{ Mitattu suure } & $\begin{array}{l}\text { Tuleva } \\
\text { jätevesi }\end{array}$ & $\begin{array}{l}\text { Lähtevä } \\
\text { jätevesi }\end{array}$ & $\begin{array}{l}\text { Reduktio } \\
\%\end{array}$ & $\begin{array}{l}\text { Kuormitus } \\
\mathrm{kg} / \mathrm{d}\end{array}$ \\
\hline $\mathrm{BOD}_{7}$ & $\mathrm{mg} / \mathrm{l}$ & 2700 & 860 & 68 & 4,3 \\
$\mathrm{COD}$ & $\mathrm{mg} / \mathrm{l}$ & 4700 & 1300 & 72 & 6,5 \\
$\mathrm{kok}-\mathrm{P}$ & $\mathrm{mg} / \mathrm{l}$ & 34 & 2,3 & 93 & 0,012 \\
$\mathrm{kok}-\mathrm{N}$ & $\mathrm{mg} / \mathrm{l}$ & 320 & 42 & 87 & 0,21 \\
$\mathrm{pH}$ & & 6,1 & 6,3 & - & \\
$\mathrm{kiintoaine}$ & $\mathrm{mg} / \mathrm{l}$ & 820 & 120 & 85 & 0,6 \\
$\begin{array}{l}\mathrm{NH}_{4}^{+} \\
\text {jätevesimäärä m} \mathrm{m}^{3} / \text { viikko }\end{array}$ & 26,5 & 8,1 & 69 & 0,04 \\
\hline
\end{tabular}

\section{Johtopäätökset}

Hankkeeseen osallistuneissa yrityksissä jätevesien käsittely oli hyvin vaihtelevaa. Erilaisia yksinkertaisia jätevedenkäsittelymenetelmiä, mm. maaperäkäsittelyä ja lammikkoja oli edelleen käytössä. Jätevedenkäsittelylaitteistojen mitoituksissa, säädöissä ja toiminnassa oli myös puutteita, eivätkä puhdistustulokset yleensä olleet tavoitetasolla. Myös ympäristölupaviranomaisten vaatimuksissa hajonta oli suurta. Kuorimoille, jotka nyt ovat hakemassa ympäristölupaa, jäteveden ja jätteiden käsittelyvaatimukset ovat korkeat. Vanhoissa luvissa, jotka ovat voimassa toistaiseksi, vaatimukset ovat yleensä vaatimattomia eikä jäteveden puhdistustuloksia juurikaan seurattu. Tämä asettaa toiminnan harjoittajat eriarvoiseen asemaan.

Jos kuorimolla ei ole mahdollisuutta johtaa jätevesiä kunnalliseen jätevedenkäsittelyyn, voidaan biologis-kemiallisella panospuhdistamolla saavuttaa ympäristölupaviranomaisten jäteveden käsittelylle asettamat vaatimukset. Hankkeessa mukana olleella panospuhdistamolla saavutettiin erinomaiset tulokset, orgaanisen aineen väheneminen oli 99,7 \%, fosforin 96,7 \% ja jopa typestä saatiin poistettua $94 \%$.

Kuorimojätevedet on esikäsiteltävä ennen kuin ne johdetaan puhdistamoon. Kiintoainetta poistetaan laskeuttamalla ja/tai kemiallisella saostuksella, myös erilaiset lingot, puristimet ja suodattimet ovat joskus tarpeellisia, jotta orgaaninen kiintoaine saadaan erilleen. Kemiallisella saostuksella ja laskeutuksella saatiin orgaanisesta aineesta poistettua noin $70 \%$ ja fosforista yli $90 \%$. Kemiallinen saostus ja laskeutus eivät kuitenkaan yksin riitä jätevedenkäsittelymenetelmiksi perunaja vihanneskuorimoille, mutta ne toimivat hyvin jätevesien esikäsittelymenetelminä ja alentavat puhdistamon kuormitusta.

Perunan ja juuresten kuorintaprosessissa sekä biologisessa jäteveden puhdistuksessa syntyy lietteitä, jotka vaativat käsittelyä. Myös ylijäämälietteen poistosta on huolehdittava. Biologinen prosessi tuottaa lietettä, n. 0,5 kg kuiva-ainetta poistettua BOD kiloa kohti. Lietteiden käsittelyllä pyritään pienentämään niiden tilavuutta ja massaa sekä mahdollisia terveys ja ympäristöhaittoja. Lietteen jatkokäsittely on ratkaistava tapauskohtaisesti.

Biologiset puhdistamot vaativat jatkuvaa seurantaa ja säännöllistä huoltoa, jotta ne toimisivat luotettavasti. Jätevesilietteen kasvua ja liukoisen hapen pitoisuutta ilmastusaltaassa on tärkeää seurata säännöllisesti, jolloin prosessissa ilmeneviin häiriöihin voidaan puuttua riittävän nopeasti

Jäteveden käsittelyn kustannukset ovat huomattavat. Puhdistamon investointikustannusten lisäksi käyttökustannukset, työpanos, sähkö, kemikaalit ja lietteen käsittely aiheuttavat jatkuvia kuluja. Kunnalliseen tai paikalliseen jätevedenkäsittelylaitokseen liittyminen osoittautui edulliseksi vaihtoehdoksi peruna- ja vihanneskuorimoille. Kuorimot sijaitsevat kuitenkin useimmiten kaukana viemäriverkostoista, jolloin tämä vaihto ei ole mahdollinen. 


\section{Kirjallisuus}

Helcom recommendation 17/10. Bssic principles for realization of BAT and BEP in fiood industry. Saatavana internetistä: http://www.helcom.fi/Recommendations/en_GB/rec17_1, luettu 10.5.2004.

Henze, M., Harrmoës, P., la Cour Jansen \& Arvin, E. 1997. Wastewater Treatment - Biological and Chemical Processes, second edition. Springer. 383 s.

Karttunen E. 2004. RIL 124-2-2004 Vesihuolto II. Suomen Rakennusinsinöörien liitto RIL ry. 684 s.

Kettunen, R., Rintala, J., Hänninen, K. \& Luostarinen, S. 2006. YMPA212 Jätevesien käsittelyprosessit ja laitokset I. Luentomoniste. Jyväskylän yliopisto, Bio- ja ympäristötieteiden laitos. $130 \mathrm{~s}$. Saatavana internetistä: http://www.jyu.fi/bio/ymp/alisivut/YMPA212\%20moniste\%202006,\%20Jatevesien\%20kasittelyprosessit\%20ja \%20laitokset.pdf , luettu 10.5.2006.

Lammentausta, J. \& Oksjoki, J. 2004. Perunankuorimojätevesien käsittely panospuhdistamossa. Pirkanmaan ympäristökeskus. Alueelliset ympäristöjulkaisut 330, 54 s.

Lehto, M., Salo, T., Sorvala, S., Kemppainen, R., Vanhala, P., Sipilä, I. \& Puumala, M. 2007. Peruna- ja juureskuorimon jätteet ja jätevedet. Maa- ja elintarviketalous 94: 77 s. $\quad$ Saatavana internetistä http://www.mtt.fi/met/pdf/met94.pdf

Loher R.C. 1974. Biological processes. In: Agricultural wastes management. Problems, processes, and approaches. Academic Press. New York. p.129-182. 